\title{
Experimental investigation of the transient thermo-mechanical behavior of a modular sensible heat storage system
}

\author{
Henok Hailemariam ${ }^{1, *}$, and Frank Wuttke ${ }^{1}$ \\ ${ }^{1}$ Geomechanics and Geotechnics, Kiel University, Ludewig-Meyn-Straße 10, 24118 Kiel, Germany
}

\begin{abstract}
This paper focuses on the experimental investigation of the transient thermo-mechanical behavior of a lab-scale prototype heat storage system. The experiment involves heating of the storage unit up to a set temperature of $70^{\circ} \mathrm{C}$ followed by a passive cooling, and monitoring the thermally induced strains and stresses in the sensible heat storage module. The results show a significant development of induced thermal strains and stresses in the heat storage unit upon heating, particularly at the interface between the embedded heating element and the soil.
\end{abstract}

\section{Introduction}

Heat demand in many places of the world is seasonal, that is, most of the heat energy is generated during the summer while the highest demand is in winter [1]. The difference between the demand and supply of heat energy is problematic for most societies of our world, forcing their continued reliance on fossil fuels and other unsustainable sources of energy.

One way of bridging this gap is via the use of clean and renewable energy schemes, such as borehole thermal energy storage (BTES) systems, where heat or cold from solar collectors or other forms of energy is stored for long periods for use in future industrial and domestic purposes [2, 3]. Detailed studies on the physical modeling of the coupled heat transfer and water flow characteristics in unsaturated soil-BTES systems were reported in [4] and [5].

Such heat storage systems are usually built at underground levels supporting structures and having load bearing capabilities. When the heat storage units or structural elements are heated and cooled, thermally induced strains and stresses are added to the already present mechanical strains and stresses due to structures built on them [6]. Therefore, careful study of the thermomechanical behavior of the heat storage systems, and soil-structure interaction studies especially at elevated temperatures are essential $[7,8]$.

In this paper, the transient thermo-mechanical behavior of a lab-scale prototype borehole thermal energy storage unit is studied experimentally. The heat transport to the app. $0.9 \mathrm{~m}^{3}$ cylindrical heat storage barrel is facilitated via an embedded cemented borehole heat exchanger (BHE) unit placed at the center of the barrel. The set-up is heated up to a maximum storage temperature of $70^{\circ} \mathrm{C}$ followed by a passive cooling, and the thermally induced strains and stresses of the soil and cemented BHE are monitored.

\section{Experimental program}

\subsection{Experimental set-up}

The solid-liquid modular thermal energy storage set-up consists of a cylindrical plastic barrel with a diameter of $100 \mathrm{~cm}$ and a height of $110 \mathrm{~cm}$, a cylindrical cemented BHE unit with a diameter of $15 \mathrm{~cm}$ and a height of 100 $\mathrm{cm}$, a $20 \mathrm{~cm}$ insulation (i.e. PROBAU Mineralwolledämmstoff soft insulation + thick Styrodur [9] hard insulation) for the top and bottom bases of the barrel, a flow meter and a 15 liter capacity CC-215B Huber heating pump [10] (Fig. 1).

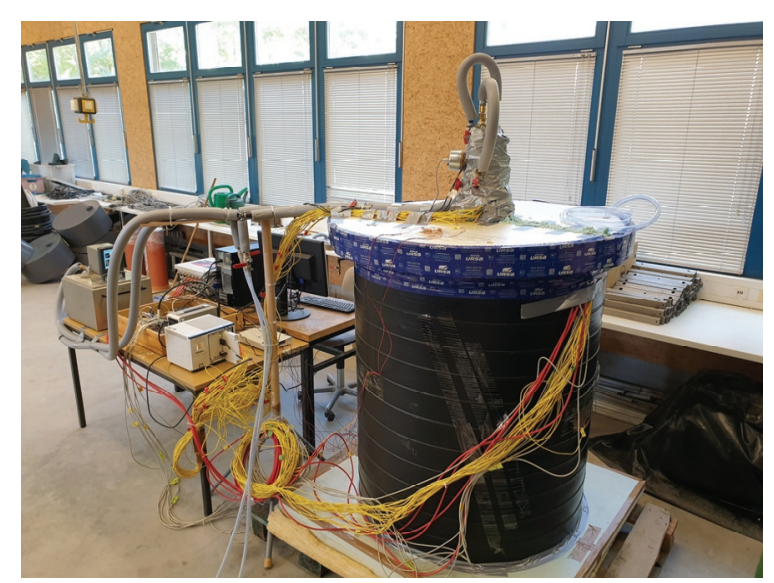

Fig. 1. Experimental set-up of the modular sensible heat storage system at Kiel University.

The barrel plastic has a side thickness of $10 \mathrm{~mm}$ and bottom thickness of $20 \mathrm{~mm}$, and is placed on a heavy duty wooden pallet (Fig. 1). The BHE unit is equipped with two independent U-shaped plastic pipes for the transport of heat to and fro the soil, and rests on $10 \mathrm{~cm}$ height of soil placed on the base of the barrel. The soil

\footnotetext{
* Corresponding author: henok.hailemariam@ifg.uni-kiel.de
} 
layer below the BHE provides extra insulation for the heat losses via the bottom face of the barrel. The heat carrier fluid, i.e. water without any additives, is circulated using the heating pump inside the BHE. To minimize heat losses, all the pipes carrying heated water were properly insulated.

A total of 32 K-type thermocouple temperature sensors [11], numbered $T_{0}$ to $T_{31}$ are used to monitor and record temperatures in the storage unit (Fig. 2). 24 of the 32 thermocouples are embedded inside the soil, 5 are embedded in the cemented BHE and 3 are placed outside the barrel to monitor boundary conditions. The thermocouple sensors are attached to a NI data acquisition unit connected to a PC, and have a measurement error of $\pm 0.45^{\circ} \mathrm{C}$ [11].

Two 1-LY41-100/120 DMS HBM linear strain gauges [12], labeled $S_{1}$ and $S_{2}$, one on the BHE-soil interface attached to the BHE and the other on the outside of the barrel are installed to monitor the thermally induced strains (Fig. 2). The strain gauges have an electrical resistance of $120 \Omega$ and a transverse sensitivity of $0.1 \%$. The strain measurements are recorded using a datalogger unit connected to the PC.

Four VW push-in pressure cell stress sensors [13], numbered $P_{1}$ to $P_{4}$, are used to monitor and record the thermally induced lateral stresses and pore-gas pressures in the soil (Fig. 2). The pressure sensors are attached to a DT2040 40 channel VW and thermistor datalogger unit connected to the PC, and have a measurement capacity of $350 \mathrm{kPa}$, and a minimum measurement resolution of $\pm 0.1 \mathrm{kPa}$.

And finally, eight CS640 three-rod $7.5 \mathrm{~cm}$ long TDR probes [14], numbered $M_{1}$ to $M_{8}$, are used to monitor and record the volumetric moisture contents in the soil (Fig. 2). The moisture content measurement set-up also includes a $12 \mathrm{Vdc}$ power supply, a TDR100 time domain reflectometer, a SDM8X50 8-channel solid state $50 \Omega$ coaxial multiplexer, and a CR800 measurement and control datalogger unit connected to the PC. The CS640 TDR set-up is capable of measuring moisture content of soils with bulk electrical conductivity of up to $5 \mathrm{dS} / \mathrm{m}$, and has a timing resolution of $12.2 \mathrm{ps}$.

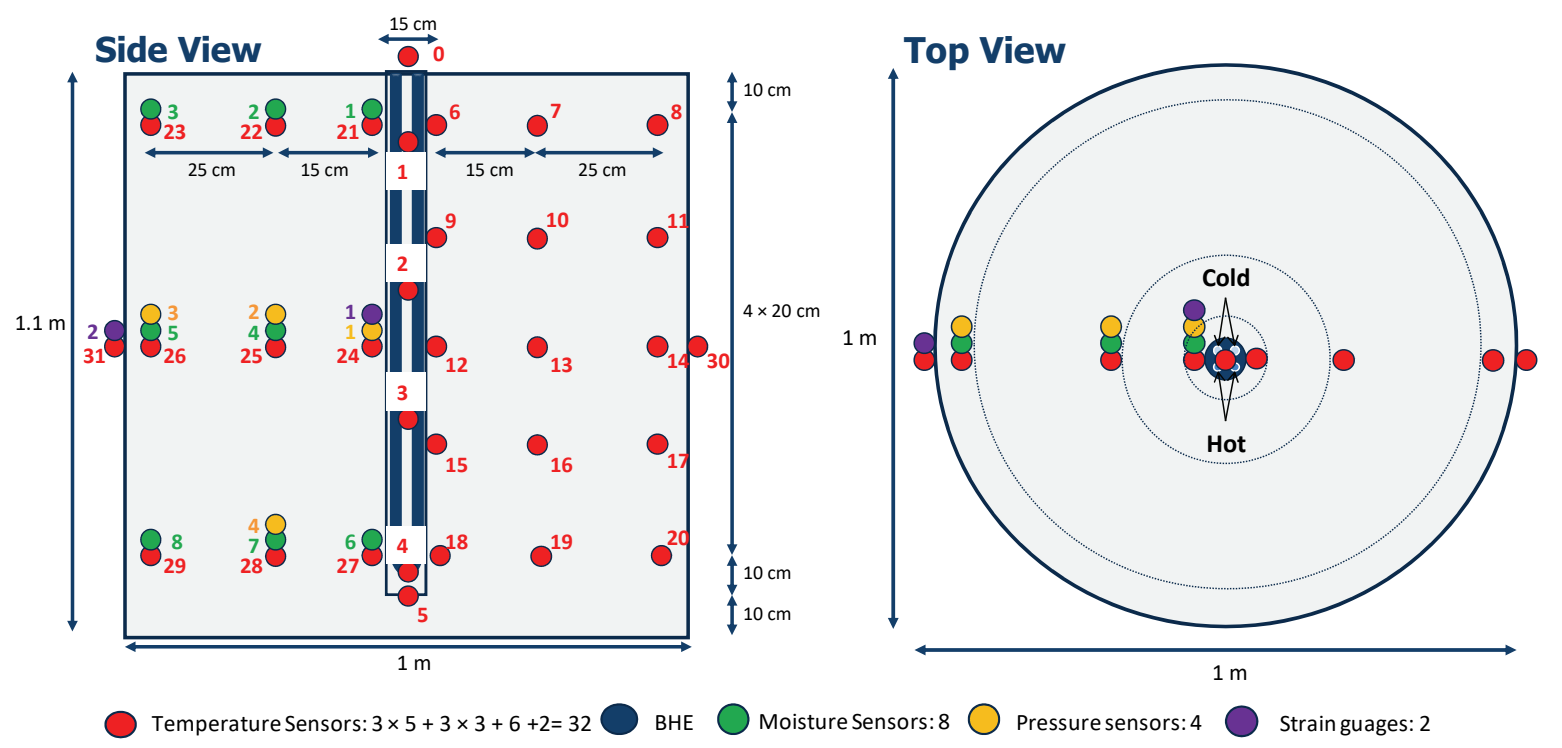

Fig. 2. Schematic representation of the sensors used for monitoring the heat storage unit.

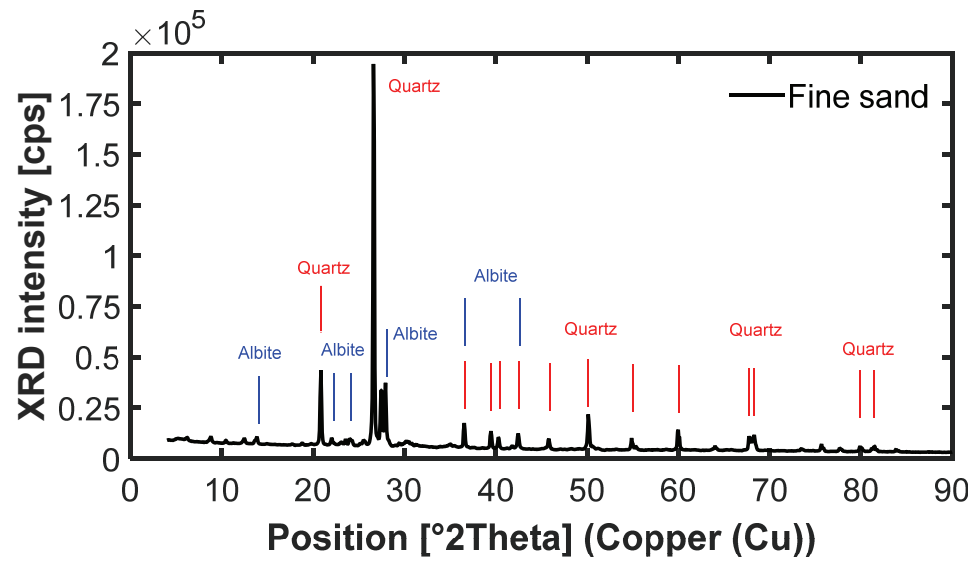

Fig. 3. X-ray diffraction (XRD) diagram of the soil. 


\subsection{Materials used}

An air dried naturally occurring fine sand was used as the heat storage medium. Table 1 shows a list of the obtained geotechnical properties of the soil, and in Figs. 3 and 4, results of X-ray diffraction (XRD) mineralogical analysis and grain size distribution of the soil are shown, respectively. The fine sand particles are primarily composed of quartz and albite minerals (Fig. $3)$.

A commercial cement-based material, named ThermoCem PLUS [15], was used to construct the BHE. After preparing the BHE using a fresh mix of the ThermoCem PLUS powder and water with a water to solids ratio of 0.802 , the BHE was cured for a minimum of 28 days to complete the cement's exothermic hydration processes and achieve its operational geotechnical properties. In Table 2, a summary of the obtained physical properties of the cemented BHE material are presented. And in Fig. 5, the set-up after the installation of the soil, BHE and the sensors is shown.

Table 1. Physical properties of the fine sand.

\begin{tabular}{|c|c|}
\hline Property & Value \\
\hline Gravel, > 2 mm (wt.\%) & 2.65 \\
\hline Sand, 0.063 - $2 \mathrm{~mm}$ (wt.\%) & 95.6 \\
\hline Silt and clay, $<0.063 \mathrm{~mm}($ wt. $\%)$ & 1.75 \\
\hline Bulk dry density $\left(\mathrm{kg} \mathrm{m}^{-3}\right)$ & 1790 \\
\hline Porosity (-) & 0.33 \\
\hline Specific gravity of solids (-) & 2.68 \\
\hline Grain diameter at $10 \%$ passing $(\mathrm{mm})$ & 0.12 \\
\hline Grain diameter at $50 \%$ passing $(\mathrm{mm})$ & 0.33 \\
\hline Coefficient of uniformity (-) & 3.33 \\
\hline Coefficient of curvature (-) & 1.30 \\
\hline Dry eff. thermal conductivity $\left(\mathrm{W} \mathrm{m}^{-1} \mathrm{~K}^{-1}\right)^{(1)}$ & 0.309 \\
\hline Dry eff. specific heat capacity $\left(\mathrm{M} \mathrm{J} \mathrm{m}^{-3} \mathrm{~K}^{-1}\right)^{(1)}$ & 1.355 \\
\hline Unified soil classification system (USCS) & $\mathrm{SP}^{(2)}$ \\
\hline
\end{tabular}

(1): measured using Decagon KD2 Pro device

(2): poorly graded sand

Table 2. Physical properties of the BHE cemented material.

\begin{tabular}{|c|c|}
\hline Property & Value \\
\hline Water to solids ratio $(-)^{(1)}$ & 0.802 \\
\hline Suspension density $\left(\mathrm{kg} \mathrm{m}^{-3}\right)$ & 1460 \\
\hline Bulk saturated density $\left(\mathrm{kg} \mathrm{m}^{-3}\right)$ & 1583 \\
\hline Effective oven-dried porosity $(-)$ & 0.605 \\
\hline Effective air-dried porosity $(-)$ & 0.397 \\
\hline Dry eff. thermal conductivity $\left(\mathrm{W} \mathrm{m}^{-1} \mathrm{~K}^{-1}\right)^{(2)}$ & 0.450 \\
\hline Dry eff. specific heat capacity $\left(\mathrm{M} \mathrm{J} \mathrm{m}^{-3} \mathrm{~K}^{-1}\right)^{(2)}$ & 1.001 \\
\hline 28-day water cured uni-axial strength $(\mathrm{MPa})$ & 3.013 \\
\hline
\end{tabular}

(1): suspension prepared by hand mixing at room temperature

(2): measured using Decagon KD2 Pro device

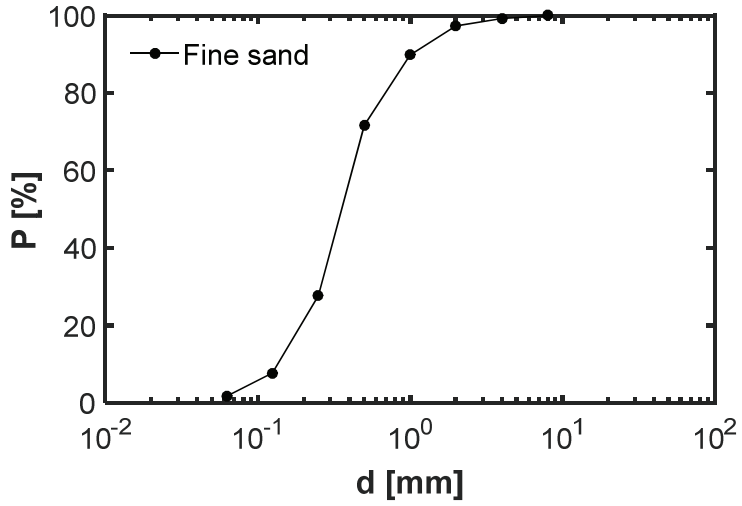

Fig. 4. Grain size distributions of the soil.

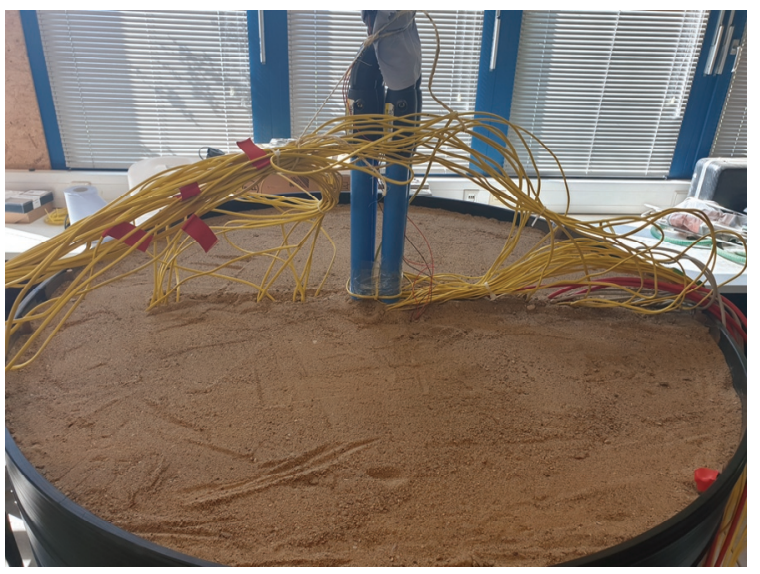

Fig. 5. Installation of the soil, sensors and the cemented BHE.

\subsection{Experimental procedure}

After an initial circulation of water without heating to remove air from the piping system, the heating phase $t_{\text {heating }}$ of the experiment was performed at the $T_{\max } 70^{\circ} \mathrm{C}$ for around 4 hours.

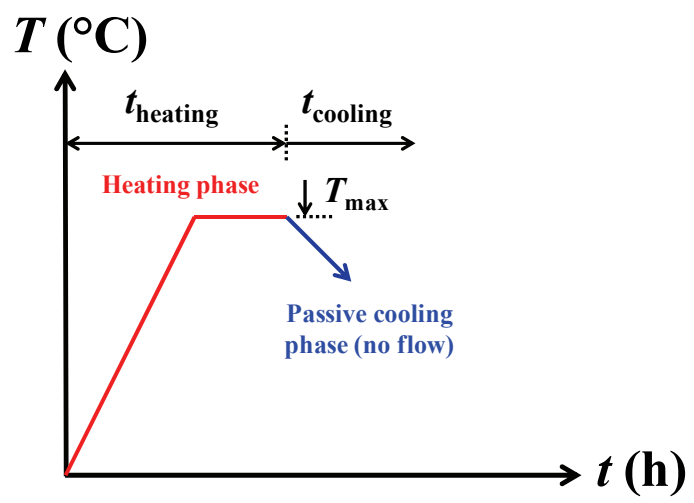

Fig. 6. Schematic representation of the adopted heating/cooling regimes of the experiment.

The duration of heating was kept relatively short in order to avoid heat reaching the lateral boundary (plastic barrel), thus avoiding extra thermally induced strains of 
the plastic barrel and replicating actual field BTES conditions. After the heating phase, the flow/heating of the fluid was stopped to start the passive cooling $t_{\text {cooling }}$ process and the data was recorded for around 46 hours. The loading procedure followed for the experiment is schematically shown in Fig. 6.

\section{Results and discussion}

\subsection{Temperature distribution}

Figure 7 shows the time plot of the temperature $T$ distributions in the heat storage soil. For the given heating duration and set heating bath temperature $T_{\max }$ $\left(70^{\circ} \mathrm{C}\right)$, a maximum temperature of around $35^{\circ} \mathrm{C}$ is recorded at the BHE-soil interface, sensor $T_{9}$ (Fig. 7, left), which is significantly lower than the average maximum temperature measured at the center of the cemented $\mathrm{BHE}\left(59^{\circ} \mathrm{C}\right)$, indicating a significant heat loss in the BHE, soil and the BHE-soil interface due to the high thermal resistance or low thermal conductivity of both the BHE cement and the surrounding soil. Whereas, the heat loss in the water carrying pipes (i.e. from the heating bath to the BHE inlet) is generally around $4^{\circ} \mathrm{C}$, which is comparatively much lower than the heat losses recorded inside the BHE, soil and BHE-soil interface.

The plots also show no considerable increase of temperature at the sensors placed near the outer lateral boundary of the system as assumed earlier (Fig. 7, right) (i.e. similar temperatures recorded at the sensors placed in the soil near the plastic barrel boundary, sensors $T_{11}$, $T_{14} \& T_{17}$, and the sensor placed outside the barrel, sensor $T_{30}$, which represents the room temperature).

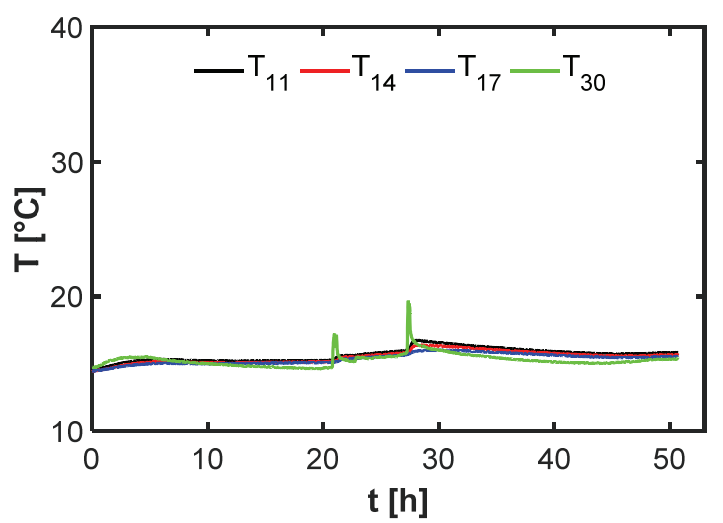

Fig. 7. Measured temperature profiles at: sensors near the BHE (left) and sensors at/near the outer boundary of the barrel (right).
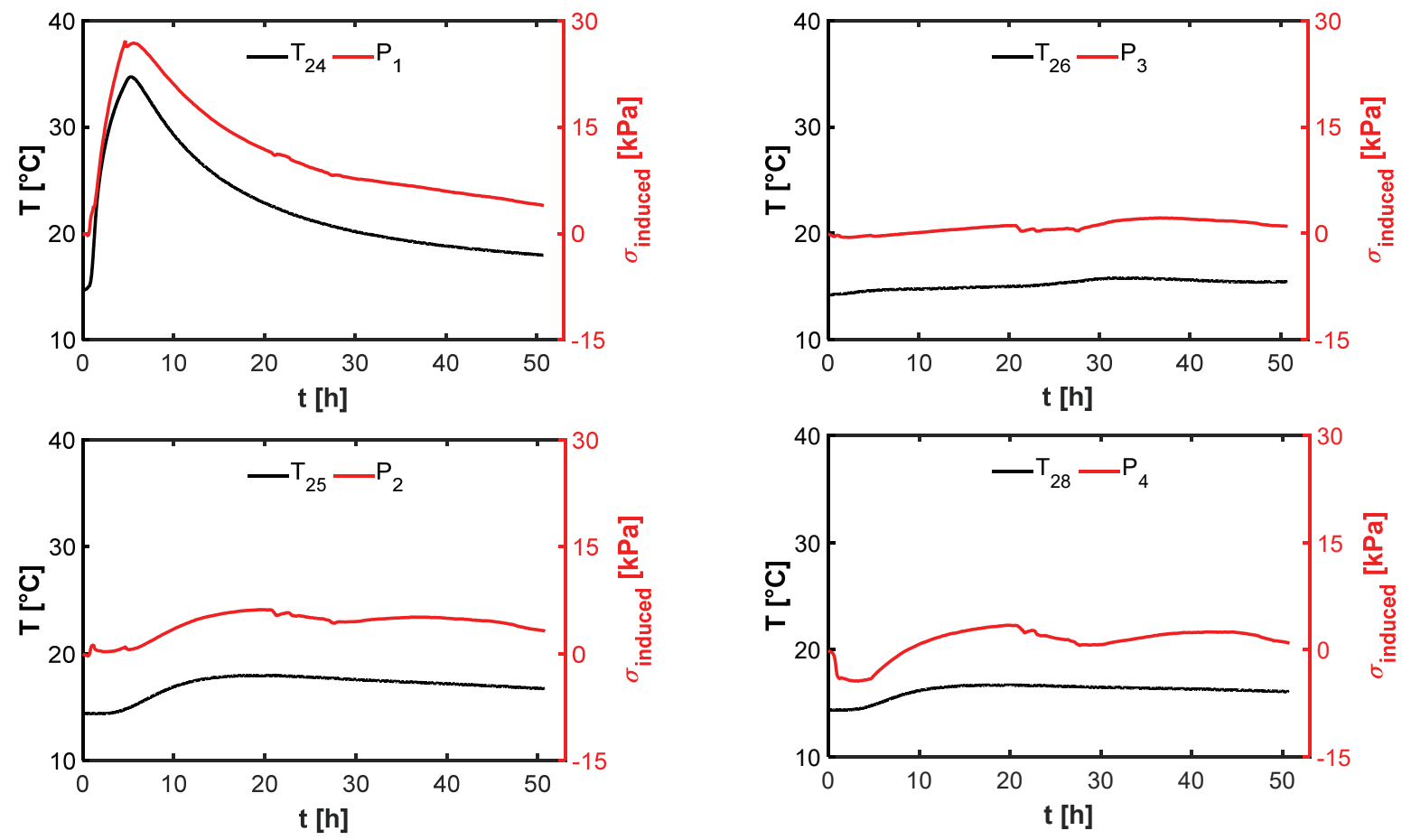

Fig. 8. Measured thermally induced lateral stress profiles at the four pressure sensors. 


\subsection{Stress distribution}

In Fig. 8, the thermally induced lateral stress profiles at the four sensor positions are shown along with their respective temperature profiles.

As expected, an increase in the measured thermally induced stress $\sigma_{\text {induced }}$ is recorded at sensors $P_{1}, P_{2}$ and $P_{4}$, following the shape of the time-temperature profile. The maximum value of $\sigma_{\text {induced }}$ is recorded at the BHEsoil interface sensor $P_{1}$ with a value of around $27 \mathrm{kPa}$, and no significant $\sigma_{\text {induced }}$ is measured at the outer boundary sensor $P_{3}$. The generated stresses are primarily attributed to the expansion and rearrangement of the quartz and albite dominated soil grains.

It should be noted that the generated stresses in the heat storage unit may not be isotropic, with the generation of induced stresses in the axial or vertical direction expected to be of different magnitudes to the radial or lateral stresses shown in this study. Due to the direction of installation of the stress sensors used in this research, however, it was not possible to measure these axial/vertical stresses. Nevertheless, considering the direction of heating, the heat insulation system and boundary conditions provided in this study, the magnitudes of the induced vertical stresses may be lower than the lateral/horizontal stresses reported in this study.

In contrast to the thermally induced stresses, very insignificant changes in the generated gas pressures $U_{\text {induced }}$ are recorded, with only around $<1 \mathrm{kPa}$ increase measured at the BHE-soil interface sensor $P_{1}$. However, unlike in this study, which was performed on a soil at or near dry moisture condition, the generation of excess gas or pore water pressures may be significant in the case of partially or fully saturated heat storage soils/systems.

\subsection{Strain distribution}

The highest thermally induced strain $\varepsilon_{\text {induced }}$ is recorded at the BHE-soil interface sensor $S_{1}$ with an average maximum value of around $270 \mu \mathrm{m} / \mathrm{m}$, once a peak temperature condition is reached in the BHE (Fig. 9, left). As expected no strain is generated at the strain sensor attached to the outside of the barrel (Fig. 9, right).

\subsection{Moisture distribution}

In Table 3, the averages of the volumetric water content $\theta$ measurements taken by the eight TDR moisture probes $M_{1}$ to $M_{8}$ throughout the test duration are shown. Overall, no significant changes in moisture content were observed at all sensor locations during the heating/cooling operation. Comparatively speaking, similar average volumetric moisture content $\theta_{\text {avg }}$ measurements were recorded by all the moisture sensors ranging at near dry conditions between 0.3 and $1.3 \%$ (corresponding to degrees of saturation $S_{r}$ between 0.9 and $3.9 \%$ ), indicating the homogeneity of the used soil.
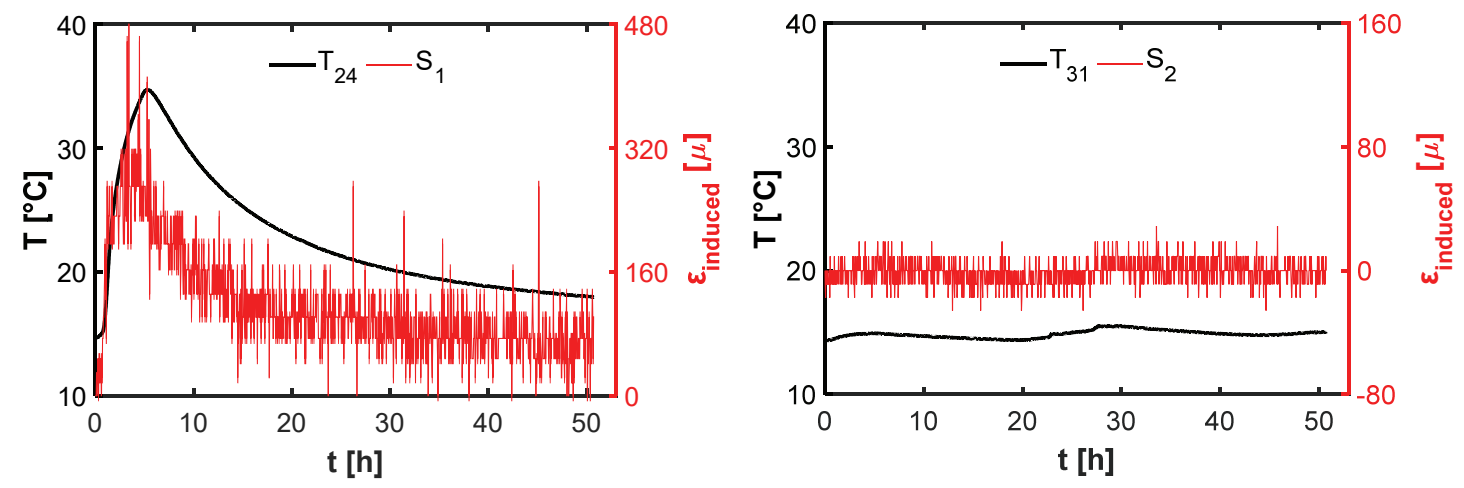

Fig. 9. Measured thermally induced strain profiles at the two strain gauges.

Table 3. Average volumetric moisture contents $\theta_{\text {avg }}$ measured at the 8 TDR probe locations.

\begin{tabular}{|c|c|}
\hline Sensor & $\boldsymbol{\theta}_{\text {avg }} \mathbf{( \% )}$ \\
\hline$M_{1}$ & 0.430 \\
\hline$M_{2}$ & 0.866 \\
\hline$M_{3}$ & 0.285 \\
\hline$M_{4}$ & 0.632 \\
\hline$M_{5}$ & 0.454 \\
\hline$M_{6}$ & 1.196 \\
\hline$M_{7}$ & 1.255 \\
\hline$M_{8}$ & 0.574 \\
\hline
\end{tabular}




\section{Conclusions}

An experimental lab-scale prototype heat storage system was set up to study the transient thermo-mechanical behavior of sensible heat storage systems. The findings of the experiment, which included heating of the storage unit up to a set temperature of $70^{\circ} \mathrm{C}$ followed by a passive cooling and monitoring the thermally induced strains and stresses of the system, indicated a significant, but tolerable, increases in the measured thermally induced strains and stresses in the heat storage unit, particularly at the borehole heat exchanger-soil interface, where maximum values of induced strain of around 270 $\mu \mathrm{m} / \mathrm{m}$ and induced stress of around $27 \mathrm{kPa}$ were recorded.

The induced stress level, which is mainly attributed to the expansion and rearrangement of the quartz and albite dominated soil grains, is equivalent to that generated by an over-burden soil pressure of around 1.5 $\mathrm{m}$ depth in field conditions, and would not be expected to cause a significant impact on the safety and operation of most sensible heat storage systems.

The authors gratefully acknowledge the financial support provided by the German Federal Ministry for Economic Affairs and Energy (BMWi) under Grant number 03ET6122A (Project ANGUS II) as well as the support of Project Management Jülich. We thank Paul Liedtke, Johannes Nordbeck, Amir Sattari, Victorien Djotsa and Bo Wang of Kiel University for their support in setting up the prototype heat storage system. We would also like to thank Kerstin Meier zu Beerentrup of Kiel University for her support in analyzing the XRD measurements.

\section{References}

1. F. Merten, C. Krüger, A. Nebel, D. Schüwer, S. Lechtenböhmer, M. Gailfuß et al., Klimapolitischer Beitrag kohlenstoffarmer Energieträger in der dezentralen Stromerzeugung sowie ihre Integration als Beitrag zur Stabilisierung der elektrischen Versorgungssysteme. Climate Change 8 (2014)

2. D. Bauer, R. Marx, J. Nußbicker-Lux, F. Ochs, W. Heidemann, H. Müller-Steinhagen, German central solar heating plants with seasonal heat storage. Solar Energy 84 (2010)

3. R. Marx, J. Nußbicker-Lux, D. Bauer, W. Heidemann, H. Drück, Saisonale Wärmespeicher Bauarten, Betriebsweise und Anwendungen. Chemie Ingenieur Technik 83 (2011)
4. T. Başer, D. Linkowski, J.S. McCartney, Charging and discharging of soil-borehole thermal energy storage systems in the vadose zone (Proceedings of the 7th International Congress on Environmental Geotechnics: ICEG 2014, Melbourne, 2014)

5. T. Başer, T. Traore, J.S. McCartney, Physical modeling of coupled heat transfer and water flow in soil-borehole thermal energy storage systems in the vadose zone, In Geothermal Energy: An Emerging Resource, Geological Society of America Special Paper 519, Boulder, CO (2016)

6. J.S. McCartney, J.S. Murphy, M.A. Stewart, Thermo-mechanical behavior of energy foundations (Proceedings of the 18th International Conference on Soil Mechanics and Geotechnical Engineering, Paris, 2013)

7. P. Bourne-Webb, B. Amatya, K. Soga, T. Amis, C. Davidson, P. Payne, Energy pile test at Lambeth College, London: Geotechnical and thermodynamic aspects of pile response to heat cycles. Géotechnique 59, 3 (2009)

8. B. Amatya, K. Soga, P. Bourne-Webb, T. Amis, L. Laloui, Thermo-mechanical behaviour of energy piles. Géotechnique 62, 6 (2012)

9. BASF, Styrodur technische daten (2019)

10. Huber Kältemaschinenbau AG, CC-215B data sheet (2019)

11. National Instruments, Thermocouple and RTD sensors data sheet (2019)

12. K. Hoffmann, Eine Einführung in die Technik des Messens mit Dehnungsmess-streifen, Hottinger Baldwin Messtechnik GmbH, HBM (1985)

13. P. Tedd, J.J. Powell, J.A. Charles, I.M. Uglow, In situ measurement of earth pressures using push-in spade-shaped pressure cells - 10 years experience, Geotechnical Instrumentation in Practice, Thomas Telford Ltd., London (1990)

14. Campbell Scientific Inc., Time domain reflectometry system (2015)

15. HeidelbergCement AG, Technical data sheet ThermoCem PLUS (2016) 